\title{
A STUDY OF ADNEXAL MASSES IN PREGNANCY
}

Shanti Sri Asuri ${ }^{1}$, P. Padmaja ${ }^{2}$, Frsha N. Taraporewalla ${ }^{3}$

\section{HOW TO CITE THIS ARTICLE:}

Shanti Sri Asuri, P. Padmaja, Frsha N. Taraporewalla "A Study of Adnexal Masses in Pregnancy". Journal of Evolution of Medical and Dental Sciences 2015; Vol. 4, Issue 46, June 08; Page: 8041-8053, DOI: $10.14260 /$ jemds/2015/1167

ABSTRACT: BACKGROUND: Adnexal masses are an uncommon cause of complications in pregnancy. Mostly ovarian in origin, they can remain asymptomatic, or can develop complications such as torsion, hemorrhage, and rarely malignancy. Ultrasound remains the mainstay for diagnosis and characterization of these masses, as well as for their follow up. Such masses can be managed conservatively, but in cases of malignancy or complications, surgical intervention becomes necessary. Early diagnosis and prompt treatment of cases can help preserve fertility, conserve the present affected pregnancy and limit malignant disease spread. AIM: The purpose of the following study is to assess the incidence and the outcome of women with adnexal masses complicating pregnancy. SUBJECTS AND METHODS: A retrospective study of women with adnexal masses complicating pregnancy was undertaken in our institute from October 1 ${ }^{\text {st }}, 2013$ to September 30 3 th 2014 , for a period of one year. RESULTS: During the study period, 8 cases were found to have adnexal masses complicating pregnancy, the incidence being $0.56 \%$. 2 cases presented with acute abdomen due to torsion (25\%). Cystectomy could be done in $37.5 \%$ of cases. The most common histological pattern observed was cystadenoma (37.5\%). There were no maternal or perinatal mortalities. CONCLUSION: The decision between expectant management and surgical management must be individualized. Asymptomatic patients with small $(<5 \mathrm{~cm})$, static or slow growing adnexal masses that appear benign on ultrasonography can be managed expectantly with close follow up and serial ultrasonograms. Complications such as torsion, hemorrhage or rapid growth with suspicion of malignancy warrant immediate surgery. Surgery beyond the first trimester is found to be safe in pregnancy, however there is always an increased risk of fetal loss/ preterm birth compared to normal healthy pregnancies KEYWORDS: Adnexal masses, Pregnancy.

INTRODUCTION: The fallopian tubes, ovaries and the surrounding connective tissues collectively are referred to as the adnexa. Adnexal masses are uncommon in pregnancy, with an incidence ranging from 1 in $1000(0.1 \%),{ }^{1}$ to 12 in $1000(1.2 \%) .{ }^{2}$ Some studies quote an incidence as high as $4 \% .{ }^{3}$ Such a wide range of incidence could be attributed to the availability and use of early prenatal ultrasonography. These adnexal masses are often detected incidentally, in asymptomatic patients. Majority of these masses are ovarian in origin and are benign. Ultrasound is an accurate and safe method for diagnosing the etiology of an adnexal mass and distinguishing benign from malignant pathology.

There are several factors that need to be taken into consideration at time of detection of these adnexal masses. These include size, symptoms if any, gestational age and sonomorphology. Most ovarian cysts detected in the $1^{\text {st }}$ trimester are physiological, and tend to resolve by the $2^{\text {nd }}$ trimester. ${ }^{4}$

Complications of adnexal masses can be torsion, rupture, hemorrhage or malignancy. Torsion is the most common complication, with a reported incidence of $3 \%$ to $25 \%,{ }^{5}$ to as high as $43 \% .{ }^{6}$ The incidence of cyst rupture is reported to be between $9 \%$ and $17 \% .^{7}$ 
Ovarian cancer, although rare, is found to be the second most common gynecologic cancer diagnosed during pregnancy. ${ }^{8}$ The incidence of malignancy is reported to be from less than $1 \%,{ }^{9}$ in some studies, to about $2-3 \%, 9,6$ in others. Sonological morphology and tumour markers, as well as serial ultrasounds are helpful in differentiating neoplastic from non-neoplastic lesions. For masses persisting into the third trimester, a 2-5\% risk of malignancy is to be expected. ${ }^{10}$

Management of these adnexal masses can be conservative or surgical. Although laparotomy has been the standard surgical procedure, laparoscopy has also found to be relatively safe in pregnancy and equally effective. ${ }^{11}$

The primary objective of the present study is to evaluate the incidence and etiology of adnexal masses complicating pregnancy in our institute during the specified study period of one year. The secondary objective is to determine the maternal and perinatal outcomes among these pregnancies.

SUBJECTS \& METHODS: Our institute is a tertiary referral center, with average antenatal outpatient strength of 1500 patients per month, with about 120 deliveries per month.

In our study period of one year, 8 adnexal masses complicating pregnancy were managed, between October $1^{\text {st }} 2013$ and September 30th 2014. Inclusion criteria were any adnexal mass greater than $5 \mathrm{~cm}$ either detected antenatally or persisting during subsequent antenatal follow-up, or incidentally during caesarian section for obstetric indications.

All the cases were treated surgically, and specimens sent for histopathological examination.

This study is a descriptive hospital-based retrospective study, with patient information collected from the medical records department. Relevant information such as age, parity, presenting symptoms, clinical and imaging (Mainly ultrasound of the pelvis and abdomen) diagnosis, gestational age at diagnosis, gestational age and mode of surgery, histology and subsequent maternal and perinatal outcome was assimilated. The assimilated information is presented in tables. Since this is a descriptive study, no statistical tests were done. The study was approved by the Institutional ethics committee.

RESULTS: A total of 8 cases were found with adnexal masses complicating pregnancy. Of the 8 cases, 3 cases were diagnosed antenatally, 1 case was diagnosed postnatal, and 4 cases were detected intraoperatively during caesarian sections.

2 cases required an emergency laparotomy due to torsion, one in the $2^{\text {nd }}$ trimester and one in the postpartum period.

4 cases were detected incidentally at the time of caesarian section for obstetric causes.

The details of the cases are given below.

\begin{tabular}{|c|c|c|c|c|}
\hline & Case 1 & Case 2 & Case 3 & Case 4 \\
\hline Age (in yrs.) & 20 & 21 & 22 & 30 \\
\hline Parity & 1 & 1 & 2 & 4 \\
\hline Booking status & Unbooked & Booked & Booked & Unbooked \\
\hline Complaints & Pain & Pain & Pain & - \\
\hline $\begin{array}{c}\text { GA at diagnosis } \\
\text { (in weeks) }\end{array}$ & Postpartum & 11 wks. & 18 wks. & 36 wks. \\
\hline $\begin{array}{c}\text { GA at surgery } \\
\text { (in weeks) }\end{array}$ & Postpartum & 11 wks. & 37 wks. & 38 wks. \\
\hline
\end{tabular}


ORIGINAL ARTICLE

\begin{tabular}{|c|c|c|c|c|}
\hline Surgery performed & Oophorectomy & $\begin{array}{c}\text { Salpingo- } \\
\text { oophorectomy }\end{array}$ & Cystectomy & $\begin{array}{c}\text { Salpingo- } \\
\text { oophorectomy }\end{array}$ \\
\hline $\begin{array}{c}\text { Size } \\
(\text { in } \mathrm{cm})\end{array}$ & $10 \times 8 \mathrm{~cm}$ & $10 \times 8 \mathrm{~cm}$ & $6 \times 6 \mathrm{~cm}$ & $15 \times 10 \mathrm{~cm}$ \\
\hline Torsion +/- & + & + & - & - \\
\hline $\begin{array}{c}\text { Histo-pathological } \\
\text { Diagnosis }\end{array}$ & $\begin{array}{c}\text { Simple } \\
\text { mucinous } \\
\text { cystadenoma }\end{array}$ & $\begin{array}{l}\text { Mature cystic } \\
\text { teratoma }\end{array}$ & $\begin{array}{l}\text { Follicular } \\
\text { cyst }\end{array}$ & $\begin{array}{c}\text { Simple } \\
\text { mucinous } \\
\text { cystadenoma }\end{array}$ \\
\hline Complications & Nil & Nil & Nil & Nil \\
\hline $\begin{array}{l}\text { GA at delivery } \\
\text { (in } \mathrm{cm} \text {.) }\end{array}$ & NA & 38 wks. & 37 wks. & 38 wks. \\
\hline $\begin{array}{l}\text { Birth Weight } \\
\text { (in kg.) }\end{array}$ & NA & $2.5 \mathrm{~kg}$. & $2.6 \mathrm{~kg}$. & $2.7 \mathrm{~kg}$. \\
\hline
\end{tabular}

CASE 1: A 20 year old patient reported to the outpatient department with the chief complaints of pain abdomen, localized more to the right iliac fossa. She had a normal vaginal delivery 14 days ago following an uneventful antenatal period. She was booked and delivered at another hospital, and had several normal antenatal scans. Clinical examination revealed an involuting uterus of 10 weeks size deviated to the left size, with a cystic mass felt in the right fornix. A screening ultrasound revealed a unilocular cystic right adnexal mass with a prominent pedicle and a positive whirlpool sign. In view of clinical and radiological evidence of torsion, an emergency laparotomy was performed. Laparotomy revealed a 10x8 cm right ovarian bilobed cyst with torsion (Refer Fig.1). Oophorectomy was performed. Histopathology revealed a simple mucinous cystadenoma.

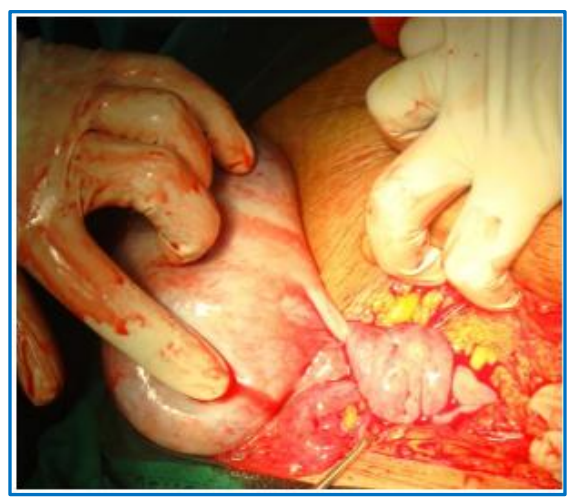

Fig. 1: Postpartum case with

ovarian cyst torsion (Case 1)

CASE 2: A 21 year old primigravida with 3 months amenorrhoea reported to the emergency services with the chief complaints of pain abdomen, localized to the right iliac fossa. Abdominal examination revealed a 16 weeks mass, deviated more towards the left. Vaginal examination revealed fullness in the right fornix, with the cervix drawn up. A screening ultrasound revealed an 11 weeks gravid uterus with a 9x7 cm sessile subserous leiomyoma in left cornual region and a 10x8 $\mathrm{cm}$ mass in the pouch of Douglas suggestive of a right ovarian mature cystic teratoma. The teratoma was confirmed using MRI. 


\section{ORIGINAL ARTICLE}

The patient was first treated conservatively for pain and discharged. The patient returned at 13 weeks gestation with severe pain abdomen and fever, with the ultrasound showing a twisted pedicle highly suggestive of torsion. An emergency laparotomy was performed. Surgery revealed a $10 \times 8 \mathrm{~cm}$ right ovarian mature cystic teratoma impacted in the pouch of Douglas with torsion. Two left cornual sessile subserous fibroids measuring $10 \times 6 \mathrm{~cm}$ and $4 \times 2 \mathrm{~cm}$ were also observed (Refer Figures 2 and 3). A salpingo-oophorectomy was performed. Histopathology confirmed the diagnosis of mature cystic teratoma. The patient had regular antenatal checkups and her remaining antenatal period was uneventful. She delivered a $2.5 \mathrm{~kg}$ healthy female baby at 38 weeks of gestation.
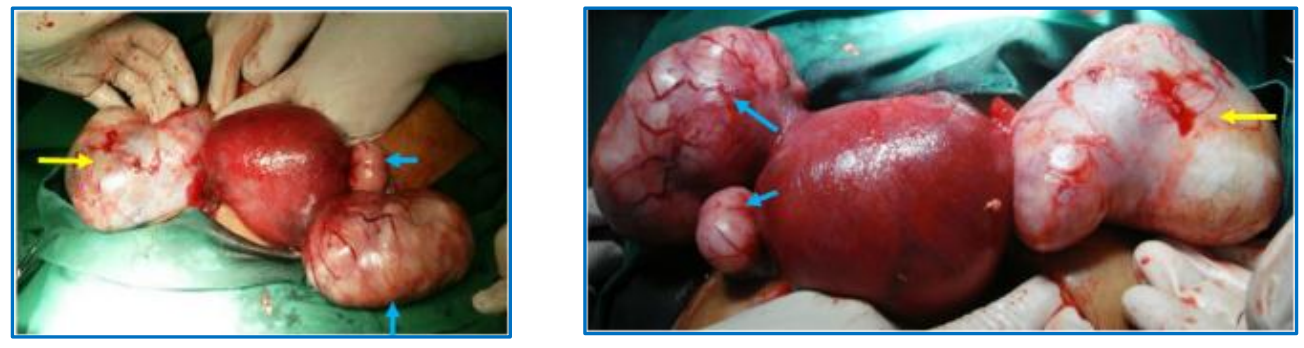

Fig. 2 \& 3: Case of ovarian torsion in $2^{\text {nd }}$ trimester (Yellow arrows), with incidental fibroids (Blue arrows) (Case 2)

CASE 3: A 22 years old G2P1L1 with 1 previous LSCS with 4 months amenorrhoea reported to the antenatal department with the complaints of pain abdomen, localized to the right iliac fossa. On abdominal examination, the uterus corresponded to 18 weeks size, with tenderness on deep palpation in the right iliac fossa. Vaginal examination revealed no other significant findings. A screening ultrasound showed an 18 weeks intrauterine gestation and a 6 x $6 \mathrm{~cm}$ unilocular anechoic simple right ovarian cyst. As the sonomorphology was benign and the patient did not appear to have any complications, she was treated conservatively and discharged after adequate counseling. The patient was carefully monitored through the antenatal period and serial ultrasounds were performed. Serial scans showed no increase in the size of the cyst or any change in its morphology.

The patient had an uneventful antenatal period, with occasional episodes of right iliac fossa pain. The patient underwent an elective caesarian section at 37 weeks, indication being cephalopelvic disproportion, and delivered a healthy $2.6 \mathrm{~kg}$ male baby. The adnexae were inspected intraoperatively. There was a 6 x $6 \mathrm{~cm}$ simple right ovarian cyst. Cystectomy was performed, and histopathology confirmed the diagnosis of simple follicular cyst.

CASE 4: A 30 years old G4P3L3 with 3 previous LSCS reported to the antenatal outpatient department in our institute for the first time at 38 weeks of gestation. She was an unbooked case, with irregular antenatal visits at other centers. The patient had an uneventful antenatal period until 9 months amennorrhoea. Previous antenatal scans were also normal. The last growth scan at 36 weeks revealed a $12 x 8 \mathrm{~cm}$ thick-walled cyst with septations with benign sonomorphology pushed up to the left hypochondrium and suggestive of an ovarian cystadenoma. The patient was asymptomatic, and was referred to our institute for further evaluation and for termination of pregnancy. Abdominal examination was inconclusive in view of the term uterus. An elective caesarian section was performed at 38 weeks of gestation, and a healthy, $2.7 \mathrm{~kg}$ male baby was delivered. There was a large, cystic lobulated left ovarian cyst measuring $15 \times 10 \mathrm{~cm}$. A salpingo-oophorectomy was performed. Histopathology confirmed the cyst to be a mucinous cystadenoma. 
ORIGINAL ARTICLE

\begin{tabular}{|c|c|c|c|c|}
\hline & Case 5 & Case 6 & Case 7 & Case 8 \\
\hline Age (in yrs.) & 24 & 20 & 26 & 27 \\
\hline Parity & 3 & 1 & 4 & 3 \\
\hline Booking status & Booked & Booked & Unbooked & Booked \\
\hline Complaints & Incidental & Incidental & Incidental & Incidental \\
\hline Surgery performed & Cystectomy & Cystectomy & $\begin{array}{c}\text { Salpingo- } \\
\text { oophorectomy }\end{array}$ & Oophorectomy \\
\hline Size (in $\mathrm{cm}$ ) & $6 \times 6 \mathrm{~cm}$ & $6 \times 6 \mathrm{~cm}$ & $8 \times 6 \mathrm{~cm}$ & $8 \times 8 \mathrm{~cm}$ \\
\hline Torsion +/- & - & - & - & - \\
\hline $\begin{array}{l}\text { Histo-pathological } \\
\text { Diagnosis }\end{array}$ & $\begin{array}{l}\text { Follicular } \\
\text { cyst }\end{array}$ & Fimbrial cyst & $\begin{array}{c}\text { Serous } \\
\text { cystadenoma }\end{array}$ & $\begin{array}{c}\text { Mature cystic } \\
\text { teratoma }\end{array}$ \\
\hline Complications & Nil & Nil & Nil & Nil \\
\hline $\begin{array}{l}\text { GA at delivery } \\
\text { (in weeks) }\end{array}$ & 37 wks. & 38 wks & 39 wks. & 37 wks. \\
\hline $\begin{array}{l}\text { Birth Weight } \\
\text { (in kg.) }\end{array}$ & $2.8 \mathrm{~kg}$. & $3.2 \mathrm{~kg}$. & $2.6 \mathrm{~kg}$. & $2.6 \mathrm{~kg}$. \\
\hline
\end{tabular}

CASE 5: A 24 years old G3P2L2 with 2 previous LSCS was admitted at 37 weeks of gestation for safe confinement. She was a booked case with regular antenatal visits. She had an uneventful antenatal period with normal antenatal scans. She was asymptomatic at the time of admission. She had an elective caesarian section at 37 weeks of gestation and delivered a healthy, $2.8 \mathrm{~kg}$ female baby. On inspection of the adnexae intraoperatively, a cystic unilocular right ovarian cyst measuring $6 \times 6 \mathrm{~cm}$ was observed. A cystectomy was performed and the specimen sent for histopathology. The histopathological diagnosis was a simple follicular cyst.

CASE 6: A 20 year old primigravida was admitted at 38 weeks of gestation for safe confinement. She was a booked case with regular antenatal visits. She was diagnosed to have gestational diabetes mellitus at 12 weeks of gestation and was managed with insulin. She had normal antenatal scans with her last growth scan showing an estimated fetal weight of $3.6 \mathrm{~kg}$. She was asymptomatic at the time of admission. A bimanual examination revealed cephalopelvic disproportion the level of pelvic inlet. The patient underwent an elective caesarian section at 38 weeks of gestation and delivered a healthy, $3.2 \mathrm{~kg}$. male baby. On inspection of the adnexae intraoperatively, a $6 \times 6 \mathrm{~cm}$ left fimbrial cyst was observed. A cystectomy was performed and the specimen sent for histopathology. Histopathology confirmed the diagnosis of a fimbrial cyst.

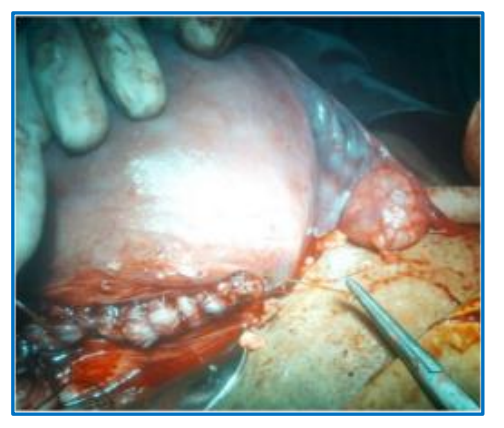

Fig. 4: Fimbrial cyst detected during caesarian (Case 6) 


\section{ORIGINAL ARTICLE}

CASE 7: A 26 year old G4P3L3 reported to our institute for the first time at 39 weeks of gestation in early labour. She was an unbooked case, with irregular checkups at other centers and had an uneventful antenatal period. Previous antenatal scans were also insignificant. A vaginal examination revealed brow presentation. An emergency caesarian section was performed in view of brow presentation in labour, and a healthy, $2.6 \mathrm{~kg}$ female baby was delivered. On inspection of the adnexae intraoperatively, the left ovary appeared enlarged $(8 \times 6 \mathrm{~cm})$ and cystic. A cystadenoma was suspected and a salpingo-oophorectomy was performed after obtaining an informed consent. Histopathology confirmed it to be a serous cystadenoma.

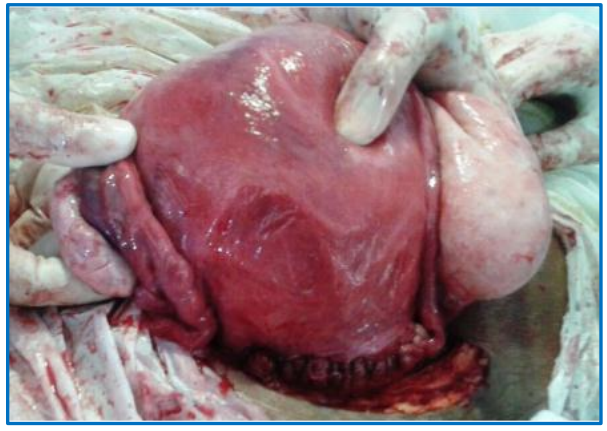

\section{Fig. 5: Cystadenoma detected during caesarian (Case 7)}

CASE 8: A 27 year old G3P2L2 was admitted at 37 weeks of gestation for safe confinement. She was a booked case with regular antenatal visits. She had an uneventful antenatal period with regular serial growth scans. She was diagnosed as Type III posterior placenta praevia at 34 weeks of gestation during one such growth scan. Patient remained asymptomatic and was closely followed up to term. In view of placenta praevia, an elective caesarian section was planned at 37 weeks of gestation. A $2.6 \mathrm{~kg}$, healthy female was delivered. On inspection of the adnexae intraoperatively, a left ovarian mass measuring 8x8 cm was observed, which was yellowish and soft in consistency. On suspicion of malignancy, an oophorectomy was performed after obtaining an informed consent. Histopathology confirmed it to be a mature cystic teratoma.

ANALYSIS OF DATA: A total of 8 cases were found with adnexal masses complicating pregnancy. With an annual delivery rate of 1440, the incidence of adnexal masses in our center for the given study period was $0.56 \%$, which is comparable to reported incidences in previous studies. ${ }^{12,13}$ The mean age of the cases was $23.75 \pm 3.06$ years (95\% Confidence Interval) with a range of 20 to 30 years and a median age of 23 years.

Of the 8 cases, 3 were diagnosed antenatally (37.5\%), 4 were detected intrapartum (50\%) and 1 was diagnosed in the postpartum period $(12.5 \%)$.

$37.5 \%$ (3 out of 8 ) cases were primigravidas (Refer Table 2).

\begin{tabular}{|c|c|c|}
\hline Parity & No. of cases $(\mathbf{n = 8})$ & Percentage \\
\hline 1 & 3 & $37.5 \%$ \\
\hline 2 & 1 & $12.5 \%$ \\
\hline 3 & 2 & $25 \%$ \\
\hline 4 & 2 & $25 \%$ \\
\hline
\end{tabular}

Table 2: Distribution of parity among the study group 


\section{ORIGINAL ARTICLE}

The mean size of the cysts was $8.63 \mathrm{~cm} \pm 2.57 \mathrm{~cm}(95 \%$ Confidence Interval) with a range of 6 to $15 \mathrm{~cm}$ and a median size of $8 \mathrm{~cm}$.

In the 4 cases diagnosed prior to surgery, pain abdomen was the commonest symptom and was present in $75 \%$ patients. Of them, 2 cases presented with torsion - one in the $2^{\text {nd }}$ trimester and one in the postpartum period. Hence, the overall incidence of torsion was $25 \%$. The ultrasonographic findings in these cases correlated well with the surgical findings, in terms of size, morphology and presence or absence of torsion.

Of the 8 cases, 7 were of ovarian origin (87.5\%), and 1 was a fimbrial cyst (12.5\%). All the 8 cases in our study group had only unilateral adnexal masses. Simple cystadenomas were the most frequent tumours found in our study group (37.5\%), followed by mature cystic teratomas (25\%) and simple follicular cysts (25\%). (Refer Table 3 )

\begin{tabular}{|c|c|c|c|c|}
\hline \multicolumn{2}{|c|}{ Histology } & No. of cases $(n=8)$ & \multicolumn{2}{|c|}{ Percentage } \\
\hline \multicolumn{5}{|c|}{ OVARIAN } \\
\hline \multirow{2}{*}{ Cystadenoma } & Mucinous & 2 & $66.7 \%$ & \multirow{2}{*}{$37.5 \%$} \\
\hline & Serous & 1 & $33.3 \%$ & \\
\hline \multicolumn{2}{|c|}{ Mature Cystic Teratoma } & 2 & \multicolumn{2}{|c|}{$25 \%$} \\
\hline \multicolumn{2}{|c|}{ Simple Follicular Cyst } & 2 & \multicolumn{2}{|c|}{$25 \%$} \\
\hline \multicolumn{5}{|c|}{ FALLOPIAN TUBE } \\
\hline \multicolumn{2}{|c|}{ Fimbrial Cyst } & 1 & \multicolumn{2}{|c|}{$12.5 \%$} \\
\hline \multicolumn{5}{|c|}{ OTHERS } \\
\hline \multicolumn{2}{|c|}{ Paraovarian } & Nil & \multicolumn{2}{|c|}{ Nil } \\
\hline
\end{tabular}

Of the 7 cases with ovarian masses, cystectomy could be performed in only 2 cases $(28.6 \%)$. Oophorectomy, with or without salpingectomy, was performed in $71.4 \%$ (5 out of 7 cases) (refer Table 4).

\begin{tabular}{|c|c|c|}
\hline Surgery & $\begin{array}{c}\text { No. of cases } \\
(\mathbf{n = 8 )}\end{array}$ & Percentage \\
\hline Cystectomy & 3 & $37.5 \%$ \\
\hline Oophorectomy & 2 & $25 \%$ \\
\hline Salpingo-oophorectomy & 3 & $37.5 \%$ \\
\hline \multicolumn{2}{|r|}{ Table 4 : Surgical interventions } \\
\hline
\end{tabular}

Majority of the surgeries ( 6 out of 8 cases - 75\%) were done at the time of caesarian section. 2 cases required an emergency laparotomy for torsion-one in the $2^{\text {nd }}$ trimester (13 weeks gestation) and one postpartum.

There was no maternal or perinatal mortalities in our study.

DISCUSSION: Adnexal masses during pregnancy can present with symptoms of pain and discomfort (due to complications such as torsion), as in 3(37.5\%) of our cases. More commonly, they can be incidental findings at time of a routine antenatal ultrasound ( 1 case $-12.5 \%$ ) or at time of an operative abdominal delivery (4 cases in our study - 50\%). 
Ultrasound is safe, cost-effective and the imaging modality of choice for the detection, determination of etiology, and for monitoring and follow up of such adnexal masses.

Detection of ovarian masses in pregnancy is directly related to the ability to visualize the ovaries. Visualization of both the ovaries is most easily possible in the first trimester when high frequency transvaginal ultrasound probes can be used, and when there is lesser interference from the gravid uterus. With transvaginal ultrasound in the first trimester, both ovaries can be adequately visualized in $95 \%$ of the cases. Transabdominal ultrasound in the first trimester has been shown to detect both the ovaries in one-third, and only one ovary in two-thirds of patients. In the second and third trimesters, the gravid uterus becomes an abdominal organ, and its growth displaces the ovaries and obscures their view on ultrasound. After the first trimester, transabdominal ultrasound was able to visualize both ovaries only $16 \%$ of patients, and in $60 \%$ of patients, neither ovary could be identified. ${ }^{14}$

Therefore, the detection of adnexal pathology via ultrasound (Smaller growths) becomes less sensitive as the gestational age increases. The incidence of adnexal pathology detected in the first trimester varies from 0.2 to $6 \%, 15$ whereas in the second and third trimesters, it is $4.1 \% .^{16}$

In our study, ultrasound detected adnexal masses in early pregnancy in 2 cases (One in $1^{\text {st }}$ trimester - 11 weeks, and one in the $2^{\text {nd }}$ trimester - 18 weeks). 1 case had normal ultrasound reports up to 36 weeks gestation, whereas 1 case had normal reports throughout pregnancy and presented in the postpartum period (Both were unbooked cases). 4 cases with normal ultrasounds were found to have adnexal masses intraoperatively ( 3 were booked cases, 1 was an unbooked case). Therefore, it is mandatory to examine the adnexae during routine antenatal ultrasounds, and at the time of caesarian section (If being conducted).

Ovarian malignancy is rare in pregnancy, but should be suspected when a complex or solid adnexal mass is identified. A complex cystic mass may contain both solid and cystic components with nodular, irregular walls and thick septations. Solid masses are uniformly filled with heterogeneous irregular echoes without any sonolucent areas. ${ }^{3}$ Although pelvic ultrasound is highly sensitive in detecting adnexal masses, its specificity in detecting malignancy is lower. ${ }^{17}$

Based on sonomorphology, several scoring systems have been developed to stratify the risk of ovarian malignancy. These scoring systems have a sensitivity of $97 \%$ for identifying a malignancy.

The positive predictive value is $29 \%$, which indicates that a significant number of benign masses have features of malignancy. The negative predictive value is $99.6 \%$, which indicates that these scoring system are able to confidently exclude malignancy. ${ }^{18}$

However, when the diagnostic performance of risk-stratification models are compared to "pattern recognition" (i.e., subjective evaluation of grayscale and Doppler flow features), the latter is found to perform better, yielding a sensitivity of around $85 \%$ and specificity of around $90 \% .19$

In our study, ultrasonological morphology was found to be accurate in $100 \%$ cases that were detected prior to surgery.

Magnetic resonance imaging (MRI) is an additional imaging modality which has been shown to be beneficial for the diagnosis of adnexal masses in pregnancy. MRI can more accurately diagnose certain pelvic masses in pregnancy (100\% vs. $71 \%$ via USG) and should be considered when the ultrasound diagnosis is uncertain. The drawback would be its cost and limited availability. ${ }^{20}$

In pregnancy, tumour markers (CA-125, alpha-fetoprotein, beta human chorionic gonadotropin) are less specific for malignancy, especially in the $1^{\text {st }}$ trimester and therefore they are not recommended. ${ }^{21}$ 


\begin{tabular}{|l|l|}
\hline \multicolumn{1}{|c|}{ Varian } & \multicolumn{1}{|c|}{ Non ovarian } \\
\hline Benign & Ectopic pregnancy \\
Functional cysts & Paraovarian cyst \\
Follicular cysts & Leiomyoma \\
Corpus luteum cysts & Hydrosalpinx \\
Theca-lutein cysts & Tubo-ovarian abscess \\
Luteomas & Peritoneal inclusion cyst \\
Hemorrhagic cysts & Diverticular abscess \\
Benign cystic teratomas & Appendiceal abscess or tumor \\
Serous cystadenomas & Fallopian tube cancer \\
Mucinous cystadenomas & Pelvic kidney \\
Endometriomas & Lymphoma \\
Malignant & \\
Epithelial & \\
Germ cell & \\
Sex cord/stromal & \\
Granulosa cell & \\
Metastatic & \\
Pseudomyxoma peritonei & \\
\hline Table 5: Differential diagnosis of an adnexal mass in pregnancy
\end{tabular}

Among the complications of adnexal masses in pregnancy, the most common is torsion. In our study, 2 cases presented with torsion (25\%), which is comparable to the findings of the study by Kumari et al.4 Torsion is also found to be more common in the $1^{\text {st }}$ trimester due to rapid growth of the uterus outside the pelvis. In one of our cases, there was torsion at the end of $1^{\text {st }}$ trimester. Torsion is suspected on clinical features as well as ultrasonological features such as an enlarged ovary with peripheral follicles or a positive whirlpool sign on Doppler.

Other complications include cyst rupture, hemorrhage, and very rarely, obstruction of labour.

The frequency of ovarian cancer in pregnancy is on average 1 in 16,000 pregnancies. ${ }^{22}$ The incidence of the various ovarian malignancies in pregnancy is related to the patient's age. Earlier studies claimed that germ cell tumors were the most common ovarian malignancy in pregnancy, followed by epithelial ovarian tumors. ${ }^{23}$ This reflected the fact that germ cell tumors occur most commonly in young women below 30 years of age, ${ }^{24}$ (Reproductive age group). More recently, it has been reported that low malignant potential tumors, a subgroup of epithelial ovarian tumors, are the most common ovarian malignancy in pregnancy, followed by invasive epithelial ovarian tumors and then germ cell tumors. ${ }^{9}$

In our study, cystadenomas were the most frequent finding ( 3 out of 8 cases $-37.5 \%$ ), with 2 cases of mucinous $(25 \%)$ and 1 case of serous $(12.5 \%)$ cystadenoma. The next most frequent neoplasm was mature cystic teratoma ( 2 out of 8 cases - 25\%).

Benign simple follicular cysts ( 2 out of 8 cases - 25\%) and fimbrial cysts ( 1 out of 8 cases -12 . $5 \%$ ) constituted the remaining. 


\section{ORIGINAL ARTICLE}

There are two lines of management for adnexal masses detected in pregnancy - expectant and surgical.

Expectant management is recommended for asymptomatic patients with small, simple, cystic masses $<5 \mathrm{~cm}$ in diameter which do not increase in size on serial scans or show any morphology suggestive of malignancy. Some authors also recommend expectant management if suspected ovarian neoplasms are detected in pregnancy. Ovarian cancers in pregnancy have a relatively favorable prognosis, with the overall mortality being $4.7 \% .{ }^{9}$ This comparatively low mortality rate is likely due to the early stage of disease, the high prevalence of low malignant potential tumors and germ cell tumors, both of which have an excellent prognosis, and the young age of the patients. Furthermore, delaying surgery until after delivery is unlikely to result in a worse prognosis unless the patient has obvious signs of metastatic disease. ${ }^{9}$ The drawbacks of expectant management would be need for regular follow up, and risk of complications such as torsion.

In our study, 1 case diagnosed with an adnexal mass with a benign morphology. On ultrasound was managed expectantly till term, and at the time of caesarian section, a cystectomy was done.

Surgical management is recommended for any adnexal mass greater than $10 \mathrm{~cm}$, in any symptomatic case, and if malignancy is strongly suspected. Ideally surgery is avoided in pregnancy because of the potential risks to the mother and fetus. Surgical interventions for adnexal masses during pregnancy are associated with an increased risk of spontaneous miscarriage, preterm labor, fetal growth restriction, and neonatal death.9,6 Surgery for an adnexal mass detected in the $1^{\text {st }}$ trimester, if possible, is best postponed to second trimester. If surgery is absolutely essential in the first trimester, progestational support is recommended till 16 weeks of pregnancy.

An open laparotomy is the more common surgical approach, however several studies have shown laparoscopy to be equally effective, ${ }^{11}$ if not better. ${ }^{25}$ Therefore, whenever possible, a laparoscopic approach should be preferred. Patients managed with laparoscopic surgery have lesser blood loss and quicker post-operative recovery with shorter hospital stay.

Fertility sparing surgeries such as cystectomies can be performed in patients in whom there is no suspicion of malignancy. In case of torsion, some authors recommend detorsion and cystectomy. However, in chronic torsion, once edema and necrosis sets in, fertility sparing surgeries might not be feasible. Excessive handling of the pregnant uterus must be avoided to prevent uterine irritability.

In our study, 7 out of 8 masses were ovarian in origin. Of them, in only 2 cases, fertilitysparing surgery (Cystectomy) could be performed (28.6\%). Both cases of torsion required an oophorectomy. In all 8 cases, the adnexal masses were unilateral. In our study, in the 1 case managed surgically in the $2^{\text {nd }}$ trimester, there were no adverse antenatal events following surgery. There was no maternal or perinatal mortality.

In case of advanced ovarian malignancy, staging and debulking should be performed, and the uterus preserved. Chemotherapy may be administered during the second and third trimesters of pregnancy in carefully selected patients. ${ }^{9}$

Ultrasound guided aspiration of an ovarian cyst during pregnancy has been shown to be safe. However, it is found to have similar results as expectant management. There is also a risk of infection, hemorrhage and preterm labor. Cyst aspiration is not recommended as a diagnostic procedure because of the cytologic similarities of many adnexal cysts and the potential risk of malignant fluid spillage. ${ }^{9}$ 
CONCLUSION: Although adnexal masses in pregnancy are uncommon, it is essential to screen all pregnant patients during routine antenatal ultrasounds, especially in the 1 st trimester, to avoid any false negatives. Small simple ovarian cysts in the $1^{\text {st }}$ trimester can be followed up with serial ultrasounds and patients must be reassured that they are likely to be physiological.

In case of doubtful diagnosis on ultrasound, an MRI must be considered. Tumor markers may not be helpful in establishing diagnosis, and are therefore not recommended.

Generally, small $(<5 \mathrm{~cm})$, asymptomatic masses can be managed expectantly. Aspiration of ovarian cysts is not recommended. Surgical management is required in large $(>10 \mathrm{~cm})$, symptomatic or suspicious masses, and in case of complications such as torsion or hemorrhage.

Wherever possible, laparoscopy and fertility-sparing surgeries must be performed. The overall pregnancy and maternal outcome in such patients is favorable.

\section{REFERENCES:}

1. Nowak M1, Szpakowski M, Wilczyński JR. Ovarian tumors in pregnancy-proposals of diagnosis and treatment. Ginekol Pol. 2004 Mar; 75 (3): 242-9.

2. Zanetta, G., Mariani, E., Lissoni, A., Ceruti, P., Trio, D., Strobelt, N. and Mariani, S. (2003), A prospective study of the role of ultrasound in the management of adnexal masses in pregnancy. BJOG: An International Journal of Obstetrics \& Gynaecology, 110: 578-583. doi: 10. 1046/j. 1471-0528. 2003. 02940. X.

3. George M Graham III. Adnexal Masses in Pregnancy: Diagnosis and Management. Donald School Journal of Ultrasound in Obstetrics and Gynaecology, October-December 2007; 1 (4): 66-74.

4. Lavery JP, Koontz WL, Layman L, Shaw L, Gumpel U. Sonographic evaluation of the adnexa during early pregnancy. Surg Gynecol Obstet. 1986 Oct; 163 (4): 319-23.

5. Kumari I, Kaur S, Mohan H, Huria A. Adnexal masses in pregnancy: a 5-year review. Aust N Z J Obstet Gynaecol 2006; 46 (1): 52-54.

6. Whitecar P, Turner S, Higby KA. Adnexal masses in pregnancy: a review of 130 cases undergoing surgical management. Am J Obstet Gynecol 1999; 181: 19-24.

7. Marino T, Craigo SD. Managing adnexal masses in pregnancy. Contemp Rev Obstet Gynecol 2000; 45: 130-143.

8. Richard Boulay, MD, Edward Podczaski, MD. Ovarian cancer complicating pregnancy. Obstetrics and Gynecology Clinics of North America. Volume 25, Issue 2, 1 June 1998, Pages 385-399.

9. Leiserowitz GS, Xing G, Cress R, Brahmbhatt B, Dalrymple JL, Smith LH. Adnexal masses in pregnancy: how often are they malignant? Gynecol Oncol. 2006 May; 101 (2): 315-21. Epub 2005 Nov. 28.

10. Grendys EC Jr, Barnes WA. Ovarian cancer in pregnancy. Division of Gynecologic Oncology, New England Medical Center, Boston, Massachusetts. The Surgical Clinics of North America [1995, 75 (1): 1-14].

11. Dr. Kevin J. Stepp, M. D. , Paul K. Tulikangas, M. D. , Jeffrey M. Goldberg, M. D. , Marjan Attaran, M. D. , Tommaso Falcone, M. D. Laparoscopy for Adnexal Masses in the Second Trimester of Pregnancy. Journal of the American Association of Gynecologic Laparoscopists. Volume 10, Issue 1, Pages 55-59, February 2003.

12. Nelson MJ, Cavalieri R, Graham D, Sanders RC. Cysts in pregnancy discovered by sonography. J Clin Ultrasound. 1986; 14: 509-12. 


\section{ORIGINAL ARTICLE}

13. Mariano T, Craigo SD. CME: managing adnexal masses in pregnancy. Contemporary OB/GYN 2000; 5: 130-43.

14. Shalev J, Blankstein J, Mashiach R, Lampley CE, Bar-Hava I, Vardimon D, Ben-Rafael Z, Meizner I. Sonographic visualization of normal-size ovaries during pregnancy. Ultrasound Obstet Gynecol 2000; 15: 523-6.

15. Condous G, Khalid A, Okaro E, Bourne T. Should we be examining the ovaries in pregnancy? Prevalence and natural history of adnexal pathology detected at first-trimester sonography. Ultrasound Obstet Gynecol 2004; 24: 62-6.

16. Hill LM, Connors-Beatty DJ, Nowak A, Tush B. The role of ultrasonography in the detection and management of adnexal masses during the second and third trimesters of pregnancy. Am J Obstet Gynecol 1998; 179: 703-7.

17. Noam Smorgick, Ron Maymon. Assessment of adnexal masses using ultrasound: a practical review. International Journal of Women's Health 2014: 6; 857-863.

18. Lerner JP, Timor-Tritsch IE, Federman A, Abramovich G. Transvaginal ultrasonographic characterization of ovarian masses with an improved, weighted scoring system. Am J Obstet Gynecol 1994; 170: 81-5.

19. Valentin L, Hagen B, Tingulstad S, Eik-Nes S. Comparison of 'pattern recognition' and logistic regression models for discrimination between benign and malignant pelvic masses: a prospective cross validation. Ultrasound Obstet Gynecol. 2001; 18: 357-365.

20. Kier R, McCarthy SM, Scoutt LM, Viscarello RR, Schwartz PE. Pelvic masses in pregnancy: MR imaging. Radiology. 1990; 176: 709-13.

21. Schmeler KM, Mayo-Smith WW, Peipert JF, Weitzen S, Manuel MD, Gordinier ME. Adnexal masses in pregnancy: surgery compared with observation. Obstet Gynecol 2005; 105: 10981103.

22. Sayar H, Lhomme C, Verschraegen CF. Malignant adnexal masses in pregnancy. Obstet Gynecol Clin N Am 2005; 32: 569-93.

23. Sayar H, Lhomme C, Verschraegen CF. Malignant adnexal masses in pregnancy. Obstet Gynecol Clin N Am 2005; 32: 569-93.

24. The Adnexal Mass Diagnosis and Treatment. Dec'07 Pearl W. Yee M. D. Inc.

25. Chen L, Ding J, Hua K. Comparative analysis of laparoscopy versus laparotomy in the management of ovarian cyst during pregnancy. J Obstet Gynaecol Res. 2014 Mar; 40 (3): 763-9. 


\section{ORIGINAL ARTICLE}

\section{AUTHORS:}

1. Shanti Sri Asuri

2. P. Padmaja

3. Frsha N. Taraporewalla

\section{PARTICULARS OF CONTRIBUTORS:}

1. Associate Professor, Department of Obstetrics and Gynaecology, Princess Esra Hospital, Deccan College of Medical Sciences.

2. Professor, Department of Obstetrics and Gynaecology, Princess Esra Hospital, Deccan College of Medical Sciences.

FINANCIAL OR OTHER COMPETING INTERESTS: None
3. Post Graduate, Department of Obstetrics and Gynaecology, Princess Esra Hospital, Deccan College of Medical Sciences.

\section{NAME ADDRESS EMAIL ID OF THE} CORRESPONDING AUTHOR:

Dr. A. Shanti Sri,

\#3-4-771/401,

Thakur Residence,

Barkatpura-500027, Hyderabad.

E-mail: shantisrinivas@gmail.com

Date of Submission: 18/05/2015.

Date of Peer Review: 19/05/2015.

Date of Acceptance: 01/06/2015.

Date of Publishing: 06/06/2015. 